\title{
Symptom Management and Supportive Care of Serious COVID-19 Patients and their Families in India
}

\author{
Naveen Salins ${ }^{1}$, Raj Kumar Mani ${ }^{2}$, Roop Gursahani ${ }^{3}$, Srinagesh Simha ${ }^{4}$, Sushma Bhatnagar ${ }^{5}$
}

\begin{abstract}
Coronavirus disease-19 (COVID-19) pandemic is causing a worldwide humanitarian crisis. Old age, comorbid conditions, end-stage organ impairment, and advanced cancer, increase the risk of mortality in serious COVID-19. A subset of serious COVID-19 patients with serious acute respiratory illness may be triaged not to receive aggressive intensive care unit (ICU) treatment and ventilation or may be discontinued from ventilation due to their underlying conditions. Those not eligible for aggressive ICU measures should receive appropriate symptom management. Early warning scores (EWS), oxygen saturation, and respiratory rate, can facilitate categorizing COVID-19 patients as stable, unstable, and end of life. Breathlessness, delirium, respiratory secretions, and pain, are the key symptoms that need to be assessed and palliated. Palliative sedation measures are needed to manage intractable symptoms. Goals of care should be discussed, and advance care plan should be made in patients who are unlikely to benefit from aggressive ICU measures and ventilation. For patients who are already in an ICU, either ventilated or needing ventilation, a futility assessment is made. If there is a consensus on futility, a family meeting is conducted either virtually or face to face depending on the infection risk and infection control protocol. The family should be sensitively communicated about the futility of ICU measures and foregoing life-sustaining treatment. Family meeting outcomes are documented, and consent for foregoing life-sustaining treatment is obtained. Appropriate symptom management enables comfort at the end of life to all serious COVID-19 patients not receiving or not eligible to receive ICU measures and ventilation.
\end{abstract}

Keywords: COVID-19, Palliative care, Supportive care, Symptom management.

Indian Journal of Critical Care Medicine (2020): 10.5005/jp-journals-10071-23400

\section{BACKGROUND}

Worldwide we are facing an unprecedented humanitarian crisis in the form of COVID-19 pandemic. ' As of March 31, 2020, approximately 800,000 population are infected with novel coronavirus, and 39,000 people died due to COVID-19 and still counting. India is probably in its initial stages of the pandemic with approximately 1,250 people infected and 32 deaths. However, estimates and mathematical models project a major humanitarian crisis in India, with millions getting affected and a proportional number dying due to COVID-19. The country has already begun preparation on a war footing, with a countrywide lockdown and social distancing measures. On the health front, India is building many exclusive COVID-19 hospitals and producing, on a mass scale, personal protective equipment and ventilators to manage the patients presenting with serious respiratory illness secondary to COVID-19. However, we need to learn from the experiences of the countries that were the epicenters of COVID-19 pandemic and translate those experiential learnings to our practice. ${ }^{2}$ In a subset of the population, COVID-19 presents with severe symptom burden and respiratory distress and not all will be eligible for aggressive intensive care management due to their underlying conditions. ${ }^{3}$ When the healthcare system is overwhelmed with COVID-19 patients, some with a serious acute respiratory illness will be triaged to receive aggressive intensive care management. However, a subset of COVID-19 patients with serious acute respiratory illness, who are elderly with multiple comorbidities, end-organ impairment, and advanced cancer may be triaged only for supportive treatment. ${ }^{4}$ Triage policy needs are set depending upon the local exigencies. ${ }^{5}$ Those with serious acute respiratory illness secondary to COVID-19 not receiving or not eligible to receive these aggressive intensive care management should receive appropriate symptom management measures. ${ }^{6}$ This article addresses the symptom management and supportive care
${ }^{1}$ Department of Palliative Medicine and Supportive Care, Kasturba Medical College, MAHE, Manipal, Karnataka, India

${ }^{2}$ Department of Critical Care and Pulmonology, Batra Hospital and Medical Research Centre, Delhi, India

${ }^{3}$ Department of Neurology, PD Hinduja National Hospital, Mumbai, Maharashtra, India

${ }^{4}$ Department of Palliative Care, Karunashraya, Bengaluru, Karnataka, India

${ }^{5}$ Department of Onco-anesthesia and Palliative Medicine, All India Institute of Medical Sciences, New Delhi, India

Corresponding Author: Sushma Bhatnagar, Department of Oncoanesthesia and Palliative Medicine, All India Institute of Medical Sciences, New Delhi, India, Phone: +91 9868398300, e-mail: sushmabhatnagar1@gmail.com

How to cite this article: Salins N, Mani RK, Gursahani R, Simha S, Bhatnagar S. Symptom Management and Supportive Care of Serious COVID-19 Patients and their Families in India. Indian J Crit Care Med 2020;24(6):435-444.

Source of support: Nil

Conflict of interest: None

strategies in patients with serious COVID-19 illness not suitable for intensive care treatment and ventilation.

\section{Need for Symptom Management and Palliative Care in Serious COVID-19 Patients}

In $81 \%$ of patients, COVID-19 causes mild or uncomplicated illness; and in around $19 \%$ of patients, it causes severe illness needing 
hospitalization. ${ }^{7}$ The overall case fatality rate of COVID-19 is $2-7 \% .{ }^{8-11}$ However, there is a steep increase in mortality in elderly patients with COVID-19. ${ }^{11}$ Although breathlessness was found in less than one third of COVID-19 patients in uncomplicated illness, it was the most common symptom in patients with COVID-19 needing ICU admissions and in nonsurvivors of COVID-19. ${ }^{12}$ An Italian survey showed that palliative care should be an integral part of disaster management in COVID-19 patients, which should be flexible and innovative to meet the rapidly rising need. ${ }^{13}$

\section{Suffering in Patients and Their Families Affected by Epidemics of Life-threatening InfECTIONS LIKE COVID-19 $9^{14}$ \\ Physical Suffering}

The physical suffering could be due to the direct effect of the illness and side-effects of the treatment. It can be mitigated by rapid assessment of symptoms and treatment and training of the emergency healthcare providers in the basics of palliative care.

\section{Psychological Suffering}

The psychological suffering could be due to stigmatization of illness, social isolation, anxiety, depression, and delirium. It can also be due to the grief associated with loss and the survivor's guilt. It can be mitigated by having protocols for rapid assessment of anxiety, depression, and delirium. Immediate steps include (a) making benzodiazepines, selective serotonin reuptake inhibitors, and haloperidol as part of the emergency and essential medications; (b) training the emergency and community healthcare providers in rapid assessment of psychological symptoms; (c) providing counseling support to people in social isolation via phone or video communication; and (d) creating support groups for the survivors and bereaved family members.

\section{Social Suffering}

The social suffering could be due to disease stigmatization, social isolation, being barred from the community due to illness, negative perception of the illness, authoritarianism, and poverty. It can be mitigated by taking steps to meet the basic needs like food, shelter, and clothing. Further steps include (a) community education about the illness and fear of illness and stigma; (b) creating voluntary social support groups; and (c) involving the community and religious leaders for social support.

\section{Spiritual Suffering}

The reasons for spiritual suffering may include loss of sense of the meaning of life, guilt, and loss of faith or anger toward God. It can be mitigated by providing spiritual support with all infection control strategies in place. One possible approach is to develop community spiritual groups and involving religious leaders who can provide spiritual support telephonically or via video chat.

\section{Palliative Care Triaging in Humanitarian Crisis like COVID-19 ${ }^{14}$}

Palliative care triaging in a humanitarian crisis like COVID-19 is classified into four categories. Serious COVID-19 patients who have severe acute respiratory illness and not responding to invasive ventilation or not eligible for ventilation because of underlying medical conditions will be coded as red and blue categories. In these patients, palliative care should be integrated with the acute services and disaster response team for rapid and emergency palliative care (Table 1).

\section{Categorizing COVid-19 Patients not Suitable for Ventilation}

According to a recent article by Tanja et al., ${ }^{15}$ COVID-19 patients not suitable for ventilation are categorized as stable, unstable, and end of life. The categorization is based on the early warning parameters recommended by the National Health Services, UK and WHO. ${ }^{16,17}$ The parameters used in categorization are $\mathrm{EWS}^{18}{ }^{18}$ respiratory rate, and oxygen saturation (Tables 2 and 3).

\section{Assessment and Management of Common Symptoms in COVID-19 Patients}

The COVID-19 patients with severe acute respiratory illness experience symptoms that need assessment and management. Breathlessness, delirium, respiratory secretions, and pain are the key symptoms that need immediate attention.

\section{Breathlessness (Algorithm 1)}

Severe acute respiratory illness of COVID-19 can present with intractable breathlessness refractory to medical management and high flow oxygen. ${ }^{19}$ The breathlessness can be assessed using dyspnea numerical scale (DNS) and verbal descriptor scale (VDS) for dyspnea intensity. ${ }^{20}$ Based on the DNS score and VDS, breathlessness is classified as mild, moderate, or severe (Table 4).

\section{Mild Breathlessness ${ }^{21}$}

Continue medical management and oxygen. Use nonpharmacological strategies like positioning (upright, sitting, leaning forward), relaxing environment, and cooling the face with a cold

Table 1: Palliative care triaging in COVID-19 situations

\begin{tabular}{llll}
\hline Category & Color code & Description & Palliative care involvement \\
\hline Immediate & Red & $\begin{array}{l}\text { Survival only possible with immediate } \\
\text { treatment }\end{array}$ & $\begin{array}{l}\text { Emergency palliative care integrated with active } \\
\text { care and disaster response }\end{array}$ \\
\hline Expectant & Blue & $\begin{array}{l}\text { Survival not possible given the care } \\
\text { available }\end{array}$ & $\begin{array}{l}\text { Emergency palliative care integrated with active } \\
\text { care and disaster response }\end{array}$ \\
\hline Delayed & Yellow & $\begin{array}{l}\text { Not in immediate danger of death but } \\
\text { treatment needed }\end{array}$ & $\begin{array}{l}\text { Palliative care as required for symptom } \\
\text { management }\end{array}$ \\
\hline Minimal & Green & $\begin{array}{l}\text { Will need medical treatment sometime } \\
\text { in the future }\end{array}$ & $\begin{array}{l}\text { Palliative care may be required for relief of } \\
\text { symptoms }\end{array}$ \\
\hline
\end{tabular}

(Adapted from the World Health Organization [WHO] guidelines for integrating palliative care and symptom relief into the response to humanitarian emergencies and crises) 
flannel. Handheld fans and portable fans are discouraged due to the risk of aerosol dispersion.

\section{Moderate Breathlessness ${ }^{22}$}

Above strategies + oral morphine for relief of distress of breathlessness $(2.5 \mathrm{mg}$ immediate release morphine twice daily to three times daily (BD-TDS) $+2.5 \mathrm{mg}$ as required (SOS) for breakthrough breathlessness and titrate the dose daily by $2.5 \mathrm{mg} / 24$ hours up to a maximum of 20 to $40 \mathrm{mg} / 24$ hours). A rapid titration may be needed if the symptoms are difficult to control. If the breathlessness is associated with anxiety, start with lorazepam $0.5 \mathrm{mg}$ bedtime (HS) and titrate the dose by $0.5 \mathrm{mg}$ upwards every day up to a maximum of $4 \mathrm{mg} / 24$ hours.

\section{Severe Breathlessness and Breathlessness in the End of Life ${ }^{23,24}$} Patients with severe breathlessness or breathlessness in the end-oflife situation will need parenteral opioids and benzodiazepines. Inj morphine 2 mg subcutaneously (SC) every 4 hourly + inj midazolam $2 \mathrm{mg}$ SC every 4 hourly + same doses SOS if the patient has breakthrough breathlessness. If the patient is in shock, intravenously (IV) route is preferred instead of subcutaneous. If a syringe driver is available, inj morphine 10-15 mg/24 hours + inj midazolam 10-15 $\mathrm{mg} / 24$ hours can be administered as a continuous infusion either SC or IV. Oral and parenteral morphine can cause constipation and vomiting. The patient should be prescribed a stimulant laxative like bisacodyl $10 \mathrm{mg} \mathrm{HS}$ prophylactically to avoid constipation. Tab or inj metoclopramide $10-20 \mathrm{mg}$ should be provided as an anticipatory prescription for morphine-associated vomiting.

\section{Delirium (Algorithm 2)}

Delirium is common in patients with acute and serious illness needing ICU care or at the end of life..$^{25}$ In COVID-19 patients, delirium may be due to sepsis, metabolic disturbances, cerebral hypoxia, or due to medications. ${ }^{26}$ Most patients may have a hypoactive or mixed type of delirium with fluctuating levels of activation. It can initially present as altered sleep-wake cycle, and patients gradually develop irritability, changes in behavior and disorientation, and difficulty in maintaining attention and can extend to altered consciousness and coma. Severe agitated delirium

Table 2: Categorizing COVID-19 patients not suitable for ventilation

\begin{tabular}{ll}
\hline Stable & (A) EWS $\leq 7 ;$ (B) $\mathrm{RR} \leq 25 /$ minute; (C) $\mathrm{O}_{2}$ saturation $>$ \\
& $88 \%$ (on $60 \%$ venturi mask) \\
Unstable & (A) EWS $>7$; (B) RR $>25 /$ minute; (C) $\mathrm{O}_{2}$ saturation $<$ \\
& $88 \%$ (on $60 \%$ venturi mask) \\
End of life & (A) ARDS; (B) $\mathrm{O}_{2}$ saturation $<70 \%$ \\
\hline
\end{tabular}

ARDS, acute respiratory distress syndrome can present with restlessness and violent behavior and managing these patients can be challenging. ${ }^{27}$ Delirium in patients with serious COVID-19 with a critical and terminal illness can be assessed using a simple 4AT test ${ }^{28}$ (Table 5).

Haloperidol is the preferred pharmacological agent for the management of agitated delirium in critical illness. ${ }^{29}$ The starting dose for delirium with mild symptoms can be as low as $0.5 \mathrm{mg} \mathrm{BD}$. The dose can be titrated up incrementally up to 10-15 mg/24 hours. In patients with severe agitation, parenteral haloperidol is preferred. ${ }^{30}$ Starting dose of $1.5-5 \mathrm{mg} \mathrm{SC}$ stat and an intermittent dose of $2.5 \mathrm{mg}$ SC every 8 hourly $(\mathrm{Q} 8 \mathrm{H})$ or every 6 hourly $(\mathrm{Q} 6 \mathrm{H})$. If the patient is in shock IV route is preferred. If the syringe driver is available, haloperidol 5-10 mg/24 hours can be given as a continuous infusion either by subcutaneous or by intravenous route. Atypical antipsychotics such as olanzapine, risperidone, and quetiapine are less preferred in delirium in critical illness. Benzodiazepines are not the first-line agents in delirium. It can be used alongside haloperidol. Midazolam 10-15 mg/24 hours as an infusion or $2 \mathrm{mg} \mathrm{Q} 4 \mathrm{H}$ can be used alongside haloperidol if the agitation is not controlled by haloperidol. ${ }^{30}$ One of the adverse effects of haloperidol in critically ill patients that should be considered is the QT interval prolongation. Use of mechanical or physical restraints is not encouraged unless absolutely necessary. It can cause harmful consequences to the patient and worsen agitation. Pharmacological restraint is preferred over the physical restraint. $^{30}$

Nonpharmacological management also plays a vital role in managing symptoms of delirium. The patient should be nursed in a quiet room with less auditory and visual excitation. A family presence in the room may not be possible due to the risk of virus transmission. Reorientation techniques and clock and calendar in the room can be beneficial. If possible, consistency of the nursing staff and a bed by the side of the window that helps patient to differentiate day and night might be helpful. ${ }^{31}$

\section{Respiratory Secretions (Algorithm 3)}

Respiratory secretions are seen in $20-90 \%$ of patients in the last days or hours of life. ${ }^{32}$ Majority of these secretions are due to nonpathological accumulated bronchial secretions that can be seldom expectorated out. ${ }^{32}$ Although it may not cause any distress

Table 4: Dyspnea numerical scale and verbal descriptor scale of breathlessness

\begin{tabular}{lcccccccccc}
\hline 0 & 1 & 2 & 3 & 4 & 5 & 6 & 7 & 8 & 9 & 10 \\
\hline None & & & Mild & & & Moderate & & \multicolumn{3}{c}{ Severe } \\
\hline
\end{tabular}

Table 3: Early warning scores ${ }^{18}$

\begin{tabular}{|c|c|c|c|c|c|c|c|}
\hline & 3 & 2 & 1 & 0 & 1 & 2 & 3 \\
\hline Temperature $\left({ }^{\circ} \mathrm{C}\right)$ & $<35$ & & $35.1-36$ & $36.1-38$ & $38.1-39$ & $>39$ & \\
\hline Heart rate (beats/min) & $<41$ & & $41-50$ & $51-90$ & $91-110$ & $111-130$ & $>130$ \\
\hline Systolic BP (mm/Hg) & $<91$ & $91-100$ & $101-110$ & $111-219$ & & & $>219$ \\
\hline Respiratory rate (breaths/minute) & $<9$ & & $9-11$ & $12-20$ & & $21-24$ & $>25$ \\
\hline Oxygen saturation (\%) & $<92$ & $92-93$ & $94-95$ & $>96$ & & & \\
\hline Supplemental oxygen & & Yes & & No & & & \\
\hline $\begin{array}{l}\text { Central nervous system (CNS) response (alert, } \\
\text { verbal, pain, and unresponsive)* }\end{array}$ & & & & A & & & VPU \\
\hline
\end{tabular}

${ }^{*} \mathrm{~A}=\mathrm{GCS} \geq 12 \mathrm{~V}-\mathrm{P}=\mathrm{GCS} 6-11 \mathrm{U}=\mathrm{GCS} 3$

AVPU, alert, verbal, pain, unresponsive; GCS, Glasgow coma scale 
Table 5: The 4AT (4A's test) for screening delirium

Item with speech or a gentle touch on the shoulder. Ask the patient to state the name and address to assist in scoring.

AMT4: Age, date of birth, place (name of the building), current year.

Attention: Asking the patients to state months of the year backward, starting at December.

Acute change or fluctuating course: Evidence of significant change or fluctuation in alertness, cognition, other mental function arising over the last 2 weeks and still evident in the last 24 hours.

$\begin{array}{ll}\text { Description } & \text { Score } \\ \begin{array}{l}\text { Normal (fully alert and not agitated throughout the } \\ \text { assessment) }\end{array} & 0\end{array}$

assessment)

Mild sleepiness $<10$ seconds after waking. Afterward normal

Clearly abnormal $\quad 4$

No mistakes $\quad 0$

1 mistake $\quad 1$

2 or more mistakes or untestable 2

Achieves 7 months or more correctly 0

Starts but scores $<7$ months. Refuses to participate $\quad 1$

Untestable (cannot start because unwell, drowsy, or 2 inattentive)

No

0

Yes

4 or above $=$ possible delirium

$1-3=$ cognitive impairment

$0=$ delirium very unlikely

4 AT, test for 4 aspects of delirium assessment

Table 6: Numerical rating scale of pain

\begin{tabular}{lcccccccccc}
\hline 0 & 1 & 2 & 3 & 4 & 5 & 6 & 7 & 8 & 9 & 10 \\
\hline None & & Mild pain & \multicolumn{3}{c}{ Moderate pain } & \multicolumn{5}{c}{ Severe pain } \\
\hline
\end{tabular}

to the patients, the families and healthcare workers are often rattled by the noise of the secretions prompting action. ${ }^{33}$

The first step in managing overt respiratory secretions is optimizing hydration. Judicious use of parenteral hydration is critical. ${ }^{34}$ Oropharyngeal suctioning is seldom beneficial as a majority of secretions are below glottis. ${ }^{35}$ Nursing interventions to prevent aspiration and repositioning are beneficial. Moving the patient from supine to lateral recumbent position with the head slightly raised encourages drainage, maintains airways, and decreases pooling of the secretions. ${ }^{36}$

Glycopyrrolate is the preferred pharmacological agent used in managing respiratory secretions. The dose is $0.2 \mathrm{mg} \mathrm{Q8H}$ or Q6H SC or IV. In severe respiratory secretions, $0.8-1.2 \mathrm{mg}$ can be used as a continuous subcutaneous or intravenous infusion. The other drugs that can be used are atropine $0.2-0.4$ SC or IV Q4H to Q6H. Atropine is less preferred as it can cross the blood-brain barrier and cause delirium. Scopolamine $0.3-0.6 \mathrm{mg}$ SC or IV also can be used $\mathrm{Q} 4 \mathrm{H}$ to $\mathrm{Q} 6 \mathrm{H}$ to decrease respiratory secretions. ${ }^{35}$

\section{Pain (Algorithm 4)}

It is estimated that up to $70 \%$ of patients admitted to ICU experience moderate to severe pain that is seldom addressed. ${ }^{37}$ The etiology of pain in an ICU setting could be multifactorial and can be due to illness per se or due to medical procedures and invasive interventions. ${ }^{38}$ Poorly controlled pain can cause physical and emotional distress and can interfere with the patient's recovery. In a conscious patient with intact cognition and verbalizing, a numerical rating scale can be used to assess pain intensity (Table 6).

In cognitively deteriorated, altered sensorium, or intubated patients, the behavioral pain scale (BPS) is used (Table 7). ${ }^{39}$

Table 7: Behavioral pain scale

\begin{tabular}{lll}
\hline Item & Description & Score \\
\hline Facial expression & Relaxed & 1 \\
& Partially tightened & 2 \\
& Fully tightened & 3 \\
& Grimacing & 4 \\
Upper limb & No movement & 1 \\
& Partially bent & 2 \\
& Fully bent with finger flexion & 3 \\
& Permanently retracted & 4 \\
Compliance with ventilation & Tolerating movement & 1 \\
& Coughing but tolerating & 2 \\
& ventilation & 3 \\
& Fighting ventilator & 3 \\
& Unable to control ventilation & 4 \\
\hline
\end{tabular}

BPS score $\leq 3=$ no pain; BPS score $6=$ unacceptable pain; BPS score $12=$ maximal pain

Mild pain is best managed with paracetamol. Oral paracetamol up to $2-4 \mathrm{~g} / 24$ hours in four divided doses can be effective in pain management. In patients who cannot take orally, paracetamol injection 2-4 g/24 hours can be given IV. ${ }^{40}$ Nonsteroidal antiinflammatory drugs are best avoided in COVID-19 patients. ${ }^{41}$ Step 2 analgesics like tramadol and tapentadol have minimal role in managing pain in an acute ICU setting. In moderate pain, oral morphine immediate release can be initiated at $5 \mathrm{mg} \mathrm{Q4H}$ after monitoring the renal functions. If the patient is unable to take orally, inj morphine can be initiated at 1-2 mg Q4H SC or IV. In severe pain, oral morphine immediate release can be started at $10 \mathrm{mg} \mathrm{Q4H}$, and if the patient is unable to take orally, inj morphine $2-2.5 \mathrm{mg}$ can be initiated Q4H SC or IV. In the presence of renal failure, fentanyl is a better analgesic as morphine metabolites are renally cleared. 
Fentanyl transdermal patch may not be an effective option as it takes around 12 hours for its onset of action and subcutaneous absorption may be ineffective in the presence of a shock. The dose of fentanyl for pain management is $0.2-0.5 \mu \mathrm{g} / \mathrm{kg} / \mathrm{hour}$ IV as a continuous infusion. Methadone may not be a safe option in critically ill patients due its complex pharmacokinetics. If the patient has coexisting neuropathic pain, gabapentin is the preferred drug with a starting dose of $100 \mathrm{mg} \mathrm{HS}$ and titrated upward by $100-300$ $\mathrm{mg} / 24$ hours up to a maximum dose of $2700-3600 \mathrm{mg} / 24$ hours. $^{42}$

\section{Intractable Symptoms (Algorithm 5)}

There will be a subset of patients who may not have relief of symptoms with the above measures and can have serious distress. These patients are managed by administering medications to induce a state of decreased awareness to relieve the suffering caused by intractable symptoms. It is known as palliative sedation. ${ }^{43}$ Uncontrolled breathlessness, intractable pain, and severe delirium are common reasons to provide palliative sedation. Before initiating palliative sedation, a thorough assessment is required to ascertain the reversibility of the clinical condition and the symptoms. Once irreversibility is established, families should be communicated about the refractoriness of illness, severity of symptoms, and the lack of effective strategies to manage the symptom within a reasonable period of time. The need for initiating sedation should be discussed in a sensitive manner and family should be encouraged to participate in decision-making. Once the family is willing, consent has to be obtained stating the clinical condition, prognostication of illness, the intractable nature of the symptoms, the proposed approach, the probable duration of sedation, and any anticipated side effects. ${ }^{44}$

Midazolam is used as the first-line agent. A stat dose of $2 \mathrm{mg}$ is administered IV, and a maintenance dose of $10-15 \mathrm{mg} / 24$ hours as a continuous intravenous infusion can be initiated. The dose of midazolam can be up/down titrated based on the depth of sedation.

Phenobarbitone is recommended as the second-line agent. A stat dose of $100 \mathrm{mg}$ is administered IV, and a maintenance dose of $400-800 \mathrm{mg} / 24$ hours can be maintained as a continuous intravenous infusion. The dose of phenobarbitone can be up/down titrated based on the depth of sedation.

Propofol can be used as a third-line agent if the symptoms are intractable with above measures, and the propofol dose of 0.5 $\mathrm{mg} / \mathrm{kg}$ is administered stat IV and maintained on 1-4 mg/hour as a continuous intravenous infusion.

The sedation should be initiated with the smallest dose as possible, and the goal is to have light sedation. Around $30 \%$ of the initial dose can be increased every hour until the desired sedation level is obtained. However, if patients have deep sedation or apneic spells, the sedation can be temporarily stopped and lightened. Opioids are never used for palliative sedation. ${ }^{45}$

\section{Emergency Toolbox for Symptom Management of Serious COVID-19 Patients ${ }^{14}$}

\section{Emergency Resources}

Personal protection equipment guidance, aerosol, and airborne infection protection guide, hand hygiene and infection control protocol, pain scale, dyspnea scale, delirium screening scale, symptom management algorithms, standard templates for a family meeting, documenting patient and family communication, and foregoing life-sustaining treatments.

\section{Emergency Medications}

Morphine (oral immediate release tablet $10 \mathrm{mg}$ and injection $10 \mathrm{mg} / \mathrm{mL}$ ), midazolam (injection $5 \mathrm{mg} / 5 \mathrm{~mL}$ ), lorazepam (tablet $0.5 \mathrm{mg}$ and $1 \mathrm{mg}$ ), metoclopramide (tablet $10 \mathrm{mg}$ and injection $5 \mathrm{mg} / \mathrm{mL}$ ), haloperidol (tablet $0.5 \mathrm{mg}, 5 \mathrm{mg}$, and injection $5 \mathrm{mg} / \mathrm{mL}$ ), paracetamol (tablet $500 \mathrm{mg}$ and $650 \mathrm{mg}$ and injection $1 \mathrm{~g} / 100 \mathrm{~mL}$ ), pantoprazole (tablet $40 \mathrm{mg}$ and injection $40 \mathrm{mg} / \mathrm{vial}$ ), dexamethasone (tablet $4 \mathrm{mg}$ and injection $4 \mathrm{mg} / \mathrm{mL}$ ), hydrocortisone (injection $100 \mathrm{mg} / \mathrm{vial}$ ), furosemide (injection $40 \mathrm{mg} / 4 \mathrm{~mL}$ ), amitriptyline (tablet $10 \mathrm{mg}$ and $25 \mathrm{mg}$ ), citalopram (tablet $10 \mathrm{mg}$ ), quetiapine (tablet $25 \mathrm{mg}$ ), olanzapine (tablet $2.5 \mathrm{mg}$ and $5 \mathrm{mg}$ ), glycopyrrolate (injection $0.2 \mathrm{mg} / \mathrm{mL}$ ), linctus codeine suspension, phenobarbitone (injection $200 \mathrm{mg} / \mathrm{mL}$ ), and naloxone (injection $0.4 \mathrm{mg} / \mathrm{mL}$ ).

\section{Emergency Equipment}

Personal protective equipment, opioid locked boxes, nasogastric tubes, urinary catheters, wound dressing, suction apparatus, portable oxygen, subcutaneous and intravenous catheters and lines, and syringe drivers, if available.

\section{Psychosocial Support to Patients with Serious COVID-19 and their Families}

Individuals and their families experiencing public health emergencies like COVID-19 situations can develop varying degrees of stress disorders and worsening of preexisting mental health conditions. It could be due to social isolation at home, hospital quarantine, or ICU admissions. Due to infection control practices, psychologists and psychiatrist may not always be able to access the patients, and these patients have to be managed remotely or through an emergency health worker having the basic skills in dealing with emotional distress. ${ }^{46}$

\section{Discussion of Goals of Care and Advance Care Planning with Patients and Their Families in Serious COVID-19 Situations}

Before shifting elderly patients with multiple comorbidities, patients with end-stage organ impairment, and patients with advanced cancer to ICU, it may be useful to discuss the goals of care and plan for treatment. ${ }^{47}$ The goals of care discussion should involve talking to the patients and their families about the nature of the treatment they would like to receive and their preferences about the place of care. ${ }^{48}$ Elderly patients with multiple comorbidities, patients with end-stage organ and patients with impairment and advanced cancer with COVID-19 should be explained the benefit and disadvantages of invasive ventilation and ICU measures, should they develop a serious acute respiratory illness. Their preferences for life-sustaining treatment should be documented. The primary purpose of advance care planning is to avoid intensive care admissions in serious COVID-19 patients who are unlikely to benefit from ICU measures and ventilation. ${ }^{49}$ The other purpose of advance care planning is to spare the patients and their families from complex triage discussions and decision-making by discussing the goals of care in advance. ${ }^{49}$ 


\section{Decision-making and Documentation of Medical Futility in Serious COVID-19 Patients}

The treating doctors, emergency physicians, or intensivists should determine the futility of initiating or continuing aggressive ICU treatment in patients with serious COVID-19. ${ }^{50}$ The futility is determined based on a combination of criteria given below. ${ }^{4}$ As there are no established medical futility criteria for serious COVID19 situations, the treating doctors should use their discretion while considering a combination of criteria.

- High sequential organ failure assessment score ${ }^{51}$

- Irreversible shock

- Progressively worsening neurological condition

- An increasing need for ventilator support

- Older age (especially age $>80$ years)

- Multiple comorbid conditions/end-stage organ impairment/ advanced cancer

- Physician prediction of a low probability of meaningful survival.

The futility should be established by the treating doctor(s) and documented in the medical records and signed. ${ }^{52}$ If there is no consensus, then a time-limited trial of intensive care treatment can be initiated, and the patient should be reassessed after 48 hours to determine the need for continuing life-sustaining measures..$^{53}$

The futility assessment and documentation in the medical records should be according to the respective hospital's end-oflife care policy and protocol. Ideally documentation in the medical records should comprise:

- A statement stating patient has serious acute respiratory illness secondary to serious COVID-19 situation with no reasonable chance of recovery. The burden or harm of initiating/ continuation of a life-sustaining treatment outweigh the possible benefits.

- Clear reason justifying the decisions and how it satisfies the futility requirements.

- Summary of treatment provided till date.

- Life-sustaining treatments provided, planned to be withheld/ withdrawn.

- Alternative symptom management strategies deployed.

\section{Communicating Medical Futility and Foregoing Life- sustaining Treatment}

After the treating doctors document the medical futility, a family meeting should be conducted. ${ }^{54}$ If possible, it should be conducted in a room that offers privacy to the family and where doctors and family members can sit and discuss. During the family meeting, following points should be addressed.

- Refractory or critical nature of the illness (based on the futility criteria provided before)

- Benefit vs burden of initiation/continuation of aggressive medical management

- Symptom relief measures as an alternative to futile needless intensive care treatment

- Myths, misconceptions about illness, or foregoing life-sustaining treatment

- Consensus/Conflict in the family about the decision to forego life-sustaining treatment

- Discussing the process of dying and symptom relief measures provided.
Table 8: What statements to avoid and use during communication

\begin{tabular}{|c|c|}
\hline Avoid & Use \\
\hline $\begin{array}{l}\text { There is nothing more we } \\
\text { can do for the patient }\end{array}$ & $\begin{array}{l}\text { We will do everything possible to take } \\
\text { care of the patient }\end{array}$ \\
\hline $\begin{array}{l}\text { You must be very strong } \\
\text { and brave now }\end{array}$ & $\begin{array}{l}\text { We understand that it is an emotional } \\
\text { time and it is ok to feel scared and } \\
\text { anxious }\end{array}$ \\
\hline $\begin{array}{l}\text { Do not worry patient will } \\
\text { die peacefully with these } \\
\text { drugs }\end{array}$ & $\begin{array}{l}\text { We will do the best we can to see that } \\
\text { the patient does not suffer and made } \\
\text { comfortable }\end{array}$ \\
\hline $\begin{array}{l}\text { You cannot be with } \\
\text { your patient. It can be } \\
\text { dangerous for you }\end{array}$ & $\begin{array}{l}\text { I am sorry that you cannot have your } \\
\text { loved one around you. We are doing } \\
\text { everything possible to protect you, } \\
\text { while we are caring for your loved one }\end{array}$ \\
\hline
\end{tabular}

(Adapted from the Italian Society of Palliative Care Guidance). More detailed scripts are available as a toolkit at vitaltalks.org (https://www. vitaltalk.org/guides/covid-19-communication-skills/)

It may not always be possible to conduct a face-to-face meeting due to infection control protocols. In these situations, these communications can happen as video chats. After the family meeting, the details of the communication with the family is documented and signed by the healthcare providers participating in the family meeting. If the team feels it necessary, they can ask the family representative to countersign the family meeting documentation (Table 8).

\section{Documentation of Foregoing Life-sustaining Treatment}

A simple consent form provided below can be used to document the decision to forego life-sustaining treatment. It can be printed as a separate form or can be printed on the case records.

- Name of the patient, address, identification document

- Place and date and time

- Reason for the decision to forego life-sustaining treatment

- Whether the patient has the capacity to make decisions and communicate

- If yes to question 4, document whether the patient has understood and agreed with the plan. Name of the patient and signature/date

- If no to question 4, document whether the surrogate/next of kin has understood and agreed with the plan. Name of the surrogate(s)/next of kin(s) and signature/date

- Countersigned below by the treating doctor(s), name, and signature/date and time

\section{End-of-life Symptom Management of Serious CoVid-19 Patients Not Ventilated or Discontinued Ventilation}

Patients who are not ventilated or discontinued from ventilation can develop severe breathlessness, delirium, and moist breathing. They can be considered a combination of medications either as a continuous infusion or as an intermittent dosing along with breakthrough medications.

Inj morphine 10 to $15 \mathrm{mg} / 24$ hours + inj midazolam 10-15 $\mathrm{mg} / 24$ hours can be combined and administered as an infusion or inj morphine $2 \mathrm{mg}+$ inj midazolam $2 \mathrm{mg} \mathrm{Q4H}$. If respiratory secretions are present, inj glycopyrrolate $0.2 \mathrm{mg}$ every $6-8$ hours. 
Table 9: Anticipatory prescription for patients with serious COVID-19 not ventilated or withdrawn from ventilator

\begin{tabular}{ll}
\hline Symptom anticipated & Treatment plan \\
\hline Pain & Inj morphine 1-2 mg SC or IV \\
Breathlessness & Inj morphine 1-2 mg SC or IV \\
Distress/agitation & Inj midazolam 1-2 mg SC or IV \\
Delirium & Inj haloperidol 1-2 mg SC or IV \\
Delirium with severe agitation & Inj haloperidol 1-2 mg SC or IV + \\
& Inj midazolam 1-2 mg SC or IV \\
Respiratory secretions & Inj glycopyrrolate $0.2 \mathrm{mg} \mathrm{SC}$ or IV \\
Nausea and vomiting & Inj metoclopramide 20 mg SC or IV \\
\hline
\end{tabular}

The breakthrough medications are given SOS for symptoms, and breakthrough medications can be given in the intervals of $1-2$ hours as required. The breakthrough doses are one sixth of the 24-hour dose.

\section{Anticipatory Prescribing}

Patients with serious COVID-19 not ventilated/withdrawn from ventilator can develop severe symptoms. These should be anticipated, and an anticipatory prescription should be provided for all the patients (Table 9).

Patients who have intractable symptoms should be managed according to the palliative sedation guidance provided in the intractable symptoms before. As palliative extubation can lead to aerosol generation, risking other health workers and families, it is recommended not to consider palliative extubation in serious acute respiratory illness of COVID-19 situations. It is recommended to decrease ventilator support gradually and continue symptom relief measures. ${ }^{55}$

\section{Anxiety and Distress among Healthcare Providers}

The healthcare providers caring for COVID-19 patients suffer anxiety and depression due to the risks to their own life, worry over risks to families, loss of morale, burnout, and compassion fatigue. A qualitative study among healthcare providers caring for Middle East respiratory syndrome coronavirus showed that healthcare providers experience prejudicial behavior, stigmatization, traumatic fear, and despair. ${ }^{56}$ The Chinese survey study showed that frontline healthcare workers caring for COVID-19 patients experienced depression, anxiety, and insomnia. ${ }^{57}$ Therefore, self-care and mental health support to the healthcare workers are crucial during this pandemic. Interventions like providing a place for healthcare staff to isolate from their families, and guaranteed provision of food, personal protective equipment, and training are helpful. They should be provided with an opportunity to debrief and receive counseling support. ${ }^{58}$

\section{Conclusion}

The COVID-19 pandemic will test human resolve over the next year and perhaps beyond. Not all patients will benefit from or be eligible for ICU care and ventilation. We provide a toolkit for the provision of basic palliative care by intensivists, pulmonologists, and other medical professionals involved in the management of these patients.

\section{References}

1. Lee TH. Creating the new normal: the clinician response to COVID-19. NEJM Catal Innovat Care Deliv 2020;1(2).
2. Wu Z, McGoogan JM. Characteristics of and important lessons from the coronavirus disease 2019 (COVID-19) outbreak in china: summary of a report of 72314 cases from the Chinese center for disease control and prevention. JAMA 2020(13). DOI: 10.1001/jama.2020.2648.

3. Ñamendys-Silva SA. Respiratory support for patients with COVID-19 infection. The Lancet Respirat Med 2020;8(4). DOI: 10.1016/S22132600(20)30110-7.

4. Truog RD, Mitchell C, Daley GQ. The toughest triage-allocating ventilators in a pandemic. New England J Med 2020. DOI: 10.1056/ NEJMp2005689.

5. White $\mathrm{DB}$, Lo B. A framework for rationing ventilators and critical care beds during the COVID-19 pandemic. JAMA 2020. DOI: 10.1001/ jama.2020.5046.

6. Anderson RM, Heesterbeek H, Klinkenberg D, Hollingsworth TD. How will country-based mitigation measures influence the course of the COVID-19 epidemic? The Lancet 2020;395(10228):931-934. DOI: 10.1016/S0140-6736(20)30567-5.

7. Sohrabi C, Alsafi Z, O'Neill N, Khan M, Kerwan A, Al-Jabir A, et al. World Health Organization declares global emergency: a review of the 2019 novel coronavirus (COVID-19). Int J Surg 2020;76:71-76. DOI: 10.1016/j.ijsu.2020.02.034

8. Mahase E. Coronavirus: COVID-19 has killed more people than SARS and MERS combined, despite lower case fatality rate. Br Med J Pub Group 2020;368:m641. DOI: 10.1136/bmj.m641.

9. Novel CPERE. The epidemiological characteristics of an outbreak of 2019 novel coronavirus diseases (COVID-19) in China. Zhonghua Liu Xing Bing Xue Za Zhi 2020;41(2):145-151.

10. Onder G, Rezza G, Brusaferro S. Case-fatality rate and characteristics of patients dying in relation to COVID-19 in Italy. JAMA 2020. DOI: 10.1001/jama.2020.4683.

11. Porcheddu R, Serra C, Kelvin D, Kelvin N, Rubino S. Similarity in case fatality rates (CFR) of COVID-19/SARS-COV-2 in Italy and China. The J Infect Develop Countr 2020;14(02):125-128. DOI: 10.3855/jidc.12600.

12. Wang D, Hu B, Hu C, Zhu F, Liu X, Zhang J, et al. Clinical characteristics of 138 hospitalized patients with 2019 novel coronavirus-infected pneumonia in Wuhan, China. JAMA 2020;323(11):1061-1069. DOI: 10.1001/jama.2020.1585.

13. Costantini M, Sleeman KE, Peruselli C, Higginson IJ. Response and role of palliative care during the COVID-19 pandemic: a national telephone survey of hospices in Italy. medRxiv 2020.

14. World Health Organization, Integrating palliative care and symptom relief into responses to humanitarian emergencies and crises: a WHO guide. 2018.

15. Tanja F-S, Nancy P, Keller N, Claudia G. Conservative management of COVID-19 patients-emergency palliative care in action. J Pain Symptom Manage 2020. DOI: 10.1016/j.jpainsymman.2020.03.030.

16. World Health Organization., Clinical management of severe acute respiratory infection (SARI) when COVID-19 disease is suspected: interim guidance, 13 March 2020. World Health Organization; 2020.

17. Williams B, Alberti G, Ball C, Ball D, Binks R, Durham L, Royal College of Physicians, National Early Warning Score (NEWS), Standardising the assessment of acute-illness severity in the NHS, London. 2012.

18. Abbott TEF, Vaid N, Ip D, Cron N, Wells M, Torrance HDT, et al. A single-centre observational cohort study of admission national early warning score (NEWS). Resuscitation 2015;92:89-93. DOI: 10.1016/j. resuscitation.2015.04.020.

19. Xu Z, Shi L, Wang Y, Zhang J, Huang L, Zhang C, et al. Pathological findings of COVID-19 associated with acute respiratory distress syndrome. Lancet Respir Med 2020;8(4):420-422. DOI: 10.1016/S22132600(20)30076-X.

20. Wysham NG, Miriovsky BJ, Currow DC, Herndon JE, Samsa GP, Wilcock $A$, et al. Practical dyspnea assessment: relationship between the 0-10 numerical rating scale and the four-level categorical verbal descriptor scale of dyspnea intensity. J Pain Symptom Manage 2015;50(4):480-487. DOI: 10.1016/j.jpainsymman.2015.04.015.

21. Davidson P, Currow D. Management of refractory dyspnoea: evidence-based interventions. Cancer Forum. Australian Cancer Society; 2010. 
22. Rocker GM, Simpson AC, Joanne Young B, Horton R, Sinuff T, Demmons J, et al. Opioid therapy for refractory dyspnea in patients with advanced chronic obstructive pulmonary disease: patients' experiences and outcomes. CMAJ Open 2013;1(1):E27. DOI: 10.9778/ cmajo.20120031.

23. Matsuda Y, Maeda I, Tachibana K, Nakao K, Sasaki Y, Sugimoto C, et al. Low-dose morphine for dyspnea in terminally ill patients with idiopathic interstitial pneumonias. J Palliat Med 2017;20(8):879-883. DOI: $10.1089 /$ jpm.2016.0432.

24. Navigante AH, Cerchietti LC, Castro MA, Lutteral MA, Cabalar ME. Midazolam as adjunct therapy to morphine in the alleviation of severe dyspnea perception in patients with advanced cancer. J Pain Symptom Manage 2006;31(1):38-47. DOI: 10.1016/j.jpainsymman.2005. 06.009.

25. Ouimet S, Kavanagh BP, Gottfried SB, Skrobik Y. Incidence, risk factors and consequences of ICU delirium. Intensive Care Med 2007;33(1):66-73. DOI: 10.1007/s00134-006-0399-8.

26. Girard TD, Thompson JL, Pandharipande PP, Brummel NE, Jackson JC, Patel MB, et al. Clinical phenotypes of delirium during critical illness and severity of subsequent long-term cognitive impairment: a prospective cohort study. Lancet Respir Med 2018;6(3):213-222. DOI: 10.1016/S2213-2600(18)30062-6.

27. Inouye SK. Delirium in older persons. New England journal of medicine 2006;354(11):1157-1165. DOI: 10.1056/NEJMra052321.

28. Bellelli G, Morandi A, Davis DHJ, Mazzola P, Turco R, Gentile S, et al. Validation of the 4AT, a new instrument for rapid delirium screening: a study in 234 hospitalised older people. Age Ageing 2014;43(4): 496-502. DOI: 10.1093/ageing/afu021.

29. Arumugam S, El-Menyar A, Al-Hassani A, Strandvik G, Asim M, Mekkodithal $A$, et al. Delirium in the intensive care unit. J Emerg Trauma Shock 2017;10(1):37-46. DOI: 10.4103/0974-2700.199520.

30. Seneff MG, Mathews RA. Use of haloperidol infusions to control delirium in critically ill adults. Ann Pharmacother 1995;29(7-8): 690-693. DOI: 10.1177/106002809502907-806.

31. Abraha I, Trotta F, Rimland JM, Cruz-Jentoft A, Lozano-Montoya I, Soiza RL, et al. Efficacy of non-pharmacological interventions to prevent and treat delirium in older patients: a systematic overview. the SENATOR project ONTOP series. PLoS ONE 2015;10(6):e0123090. DOI: 10.1371/journal.pone.0123090.

32. Wildiers $\mathrm{H}$, Menten J. Death rattle: prevalence, prevention and treatment. J Pain Symptom Manage 2002;23(4):310-317. DOI: 10.1016/ s0885-3924(01)00421-3.

33. Clark K, Butler M. Noisy respiratory secretions at the end of life. Curr Opin Support Palliat Care 2009;3(2):120-124. DOI: 10.1097/ SPC.0b013e32832af251.

34. Lanuke K, Fainsinger RL, DeMoissac D. Hydration management at the end of life. J Palliat Med 2004;7(2):257-263. DOI: 10.1089/109662104773709378.

35. Arcuri JF, Abarshi E, Preston NJ, Brine J, Di Lorenzo VAP. Benefits of interventions for respiratory secretion management in adult palliative care patients - a systematic review. BMC Palliat Care 2016;15(1):74. DOI: 10.1186/s12904-016-0147-y.

36. Nunn C. It's not just about pain: symptom management in palliative care. Nurse Prescribing 2014;12(7):338-344. DOI: 10.12968/ npre.2014.12.7.338.

37. Freire AX, Afessa B, Cawley P, Phelps S, Bridges L. Characteristics associated with analgesia ordering in the intensive care unit and relationships with outcome. Crit Care Med 2002;30(11):2468-2472. DOI: 10.1097/00003246-200211000-00011.

38. Barr J, Fraser GL, Puntillo K, Ely EW, Gélinas C, Dasta JF, et al. Clinical practice guidelines for the management of pain, agitation, and delirium in adult patients in the intensive care unit. Crit Care Med 2013:41(1):263-306. DOI: 10.1097/CCM.0b013e3182783b72.

39. Young J, Siffleet J, Nikoletti S, Shaw T. Use of a behavioural pain scale to assess pain in ventilated, unconscious and/or sedated patients. intensive and critical care. Nursing 2006;22(1):32-39. DOI: 10.1016/ j.iccn.2005.04.004.
40. Hajiesmaeili MR, Safari S. Pain management in the intensive care unit: do we need special protocols? Anesth Pain Med 2012;1(4):237-238. DOI: 10.5812/aapm. 4523.

41. Day M. COVID-19: ibuprofen should not be used for managing symptoms, say doctors and scientists. Br Med J Publish Group 2020. DOI: $10.1136 /$ bmj.m1086.

42. Pasero C, Puntillo K, Li D, Mularski RA, Grap MJ, Erstad BL, et al. Structured approaches to pain management in the ICU. Chest 2009;135(6):1665-1672. DOI: 10.1378/chest.08-2333.

43. Cherny NI, Radbruch L, BotEAfP Care. European association for palliative care (EAPC) recommended framework for the use of sedation in palliative care. Palliat Med 2009;23(7):581-593. DOI: 10.1177/0269216309107024.

44. Cherny NI. ESMO clinical practice guidelines for the management of refractory symptoms at the end of life and the use of palliative sedation. Ann Oncol 2014;25(suppl_3):iii143-iii152. DOI: 10.1093/ annonc/mdu238.

45. Schildmann EK, Schildmann J, Kiesewetter I. Medication and monitoring in palliative sedation therapy: a systematic review and quality assessment of published guidelines. J Pain Symptom Manage 2015;49(4):734-746. DOI: 10.1016/j.jpainsymman.2014.08.013.

46. Duan L, Zhu G. Psychological interventions for people affected by the COVID-19 epidemic. The Lancet Psychiatry 2020;7(4):300-302. DOI: 10.1016/S2215-0366(20)30073-0.

47. You JJ, Fowler RA, Heyland DK. Just ask: discussing goals of care with patients in hospital with serious illness. CMAJ 2014;186(6):425-432. DOI: 10.1503/cmaj.121274.

48. Curtis JR, Downey L, Back AL, Nielsen EL, Paul S, Lahdya AZ, et al. Effect of a patient and clinician communication-priming intervention on patient-reported goals-of-care discussions between patients with serious illness and clinicians: a randomized clinical trial. JAMA Int Med 2018;178(7):930-940. DOI: 10.1001/jamainternmed.2018.2317.

49. Borasio GD, Gamondi C, Obrist M, Jox R. COVID-19: decision making and palliative care. Swiss Med Wkly 2020;150(1314). DOI: 10.4414/ smw.2020.20233.

50. Lesage P, Portenoy RK. Ethical challenges in the care of patients with serious illness. Pain Medicine 2001;2(2):121-130. DOI: 10.1046/j.15264637.2001.002002121.x.

51. Singer AJ, Ng J, Thode JrHC, Spiegel R, Weingart S. Quick SOFA scores predict mortality in adult emergency department patients with and without suspected infection. Ann Emerg Med 2017;69(4):475-479. DOI: 10.1016/j.annemergmed.2016.10.007.

52. Melltorp G, Nilstun T. Decisions to forego life-sustaining treatment and the duty of documentation. Intens Care Med 1996;22(10): 1015-1019. DOI: 10.1007/bf01699221.

53. Curtis JR, Rubenfeld GD. "No escalation of treatment" as a routine strategy for decision-making in the ICU: con. Intensive Care Med 2014;40(9):1374-1376. DOI: 10.1007/s00134-014-3421-6.

54. Machare Delgado E, Callahan A, Paganelli G, Reville B, Parks SM, Marik PE. Multidisciplinary family meetings in the ICU facilitate end-of-life decision making. Am J Hosp Palliat Med 2009;26(4):295-302. DOI: 10.1177/1049909109333934.

55. Tran K, Cimon K, Severn M, Pessoa-Silva CL, Conly J. Aerosol generating procedures and risk of transmission of acute respiratory infections to healthcare workers: a systematic review. PLoS ONE 2012;7(4). DOI: 10.1371/journal.pone.0035797.

56. Almutairi AF, Adlan AA, Balkhy HH, Abbas OA, Clark AM. "It feels like I'm the dirtiest person in the world.": Exploring the experiences of healthcare providers who survived MERS-CoV in Saudi Arabia. J Inf Public Health 2018;11(2):187-191. DOI: 10.1016/j.jiph.2017.06.011.

57. Lai J, Ma S, Wang Y, Cai Z, Hu J, Wei N, et al. Factors associated with mental health outcomes among health care workers exposed to coronavirus disease 2019. JAMA Network Open 2020;3(3). DOI: 10.1001/jamanetworkopen.2020.3976 e203976-e.

58. Chen Q, Liang M, Li Y, Guo J, Fei D, Wang L, et al. Mental health care for medical staff in china during the COVID-19 outbreak. The Lancet Psychiatry 2020;7(4):e15-e16. DOI: 10.1016/S2215-0366(20)30078-X. 
Algorithm 1: Management of breathlessness in patients with serious COVID-19 infections

\begin{tabular}{|c|c|c|c|}
\hline $\begin{array}{l}\text { Mild } \\
\text { DNS score 1-4/VDS mild }\end{array}$ & $\begin{array}{l}\text { Moderate } \\
\text { DNS score 5-6/NDS moderate }\end{array}$ & $\begin{array}{l}\text { Severe } \\
\text { DNS score } 7 \text { and above/VDS severe }\end{array}$ & $\begin{array}{l}\text { Intractable breathlessness } \\
\text { not amenable to palliative } \\
\text { management }\end{array}$ \\
\hline $\begin{array}{l}\text { - } \text { Medical management } \\
\text { - } \\
\text { - Positioning (low oxygen } \\
\text { sitting, leaning forward) } \\
\text { - Cold flannel on the face }\end{array}$ & $\begin{array}{l}\text { - Strategies used for mild + oral } \\
\text { morphine immediate release } \\
2.5 \mathrm{mg} \text { BD-TDS }+2.5 \mathrm{mg} \text { SOS. Slow } \\
\text { upward titration by } 2.5 \mathrm{mg} \text { daily up } \\
\text { to } 40-60 \mathrm{mg} / \text { day. If pain is present, } \\
\text { titration according to pain scores/ } \\
\text { pain relief } \\
\text { - Oral lorazepam } 0.5 \mathrm{mg} \text { if anxiety is } \\
\text { present. Increase by } \\
0.5 \mathrm{mg} \text { daily up to } 4 \mathrm{mg} / \text { day. } \\
\text { - Tab metoclopramide } 10 \mathrm{mg} \mathrm{SOS} \\
\text { for nausea and vomiting } \\
\text { - Tab bisacodyl } 10 \mathrm{mg} \mathrm{HS}\end{array}$ & $\begin{array}{l}\text { - Strategies used for mild + Inj } \\
\text { morphine } 2 \mathrm{mg} \\
\text { SC Q4H + Inj midazolam } 2 \mathrm{mg} \\
\text { SC Q4H } \\
\text { - If syringe driver is available } \\
\text { Inj morphine } 10-15 \mathrm{mg}+ \\
\text { Inj midazolam } 10-15 \mathrm{mg} \text { as a } \\
24 \text { hours infusion } \\
\text { - Inj metoclopramide } 20 \mathrm{mg} \\
\text { IV SOS for vomiting } \\
\text { - T bisacodyl } 10 \text { mg SOS } \\
\text { - Other strategies for } \\
\text { managing constipation if } \\
\text { patient is unable to take oral } \\
\text { bisacodyl }\end{array}$ & $\begin{array}{l}\text { See Algorithm 5: management } \\
\text { of intractable symptoms }\end{array}$ \\
\hline
\end{tabular}

Algorithm 2: Management of delirium and agitation in patients with serious COVID-19 infections

\begin{tabular}{|c|c|c|c|}
\hline Mild delirium & Delirium with agitation & $\begin{array}{l}\text { Agitation/restlessness without } \\
\text { delirium }\end{array}$ & $\begin{array}{l}\text { Intractable delirium } \\
\text { and agitation }\end{array}$ \\
\hline $\begin{array}{l}\text { Non-pharmacological: } \\
\text { - } \text { Quiet room } \\
\text { - } \text { Less visual/auditory excitation } \\
\text { - } \text { Bed by the side of window } \\
\text { - Consistency of the nursing staff } \\
\text { - } \text { Avoiding physical restraints } \\
\text { Pharmacological: } \\
\text { - Oral haloperidol } 0.5 \text { mg BD } \\
\text { and titrate dose upwards to a } \\
\text { maximum of } 10-15 \text { mg/24 hours } \\
\text { - Avoid benzodiazepines if } \\
\text { possible }\end{array}$ & $\begin{array}{l}\text { Non-pharmacological strategies for } \\
\text { mild delirium + } \\
\text { Pharmacological: } \\
\text { • Inj haloperidol } 2.5 \text { mg SC } \\
\text { Q6H-Q8H } \\
\text { - If syringe driver is available } \\
\text { Inj haloperidol 5-10 mg/ } \\
24 \text { hours continuous SC or IV } \\
\text { infusion } \\
\text { - If agitation not controlled } \\
\text { add Inj midazolam } 2 \text { mg SC/ } \\
\text { IV Q4H or as continuous SC/ } \\
\text { IV infusion } 10-15 \text { mg/24 } \\
\text { hours }\end{array}$ & 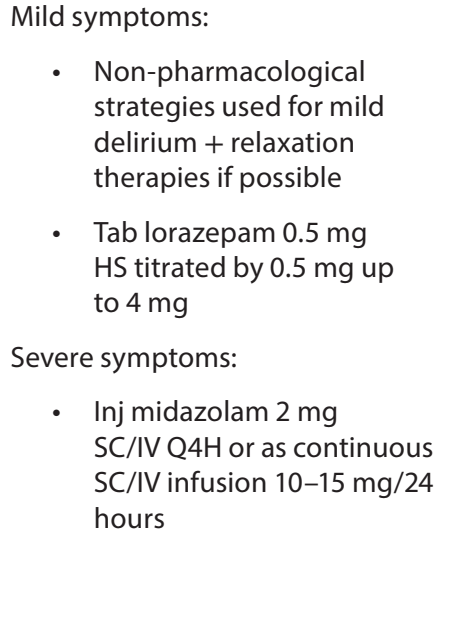 & $\begin{array}{l}\text { See Algorithm 5: } \\
\text { management of } \\
\text { intractable symptoms }\end{array}$ \\
\hline
\end{tabular}

Algorithm 3: Management of respiratory secretions in patients with serious COVID-19 infections

\begin{tabular}{|c|c|}
\hline Non-pharmacological & Pharmacological \\
\hline Optimizing hydration & - Inj glycopyrrolate 0.2 mg Q8H to Q6H SC or IV. If severe, \\
\hline - Judicious use of parenteral hydration & $\begin{array}{l}0.8-1.4 \mathrm{mg} / 24 \text { hours in divided doses or as a continuous SC } \\
\text { or IV infusion over } 24 \text { hours }\end{array}$ \\
\hline - Avoiding oropharyngeal suctioning & - Inj atropine $0.2-0.4 \mathrm{mg} \mathrm{SC}$ or IV Q4H to $\mathrm{Q} 6 \mathrm{H}$ \\
\hline - Preventing aspiration & - Inj scopolamine $0.3-0.6 \mathrm{mg}$ SC or IV Q4H to Q6H \\
\hline - Lateral recumbent position head slightly raised & \\
\hline
\end{tabular}


Algorithm 4: Management of pain in patients with serious COVID-19 infections

\begin{tabular}{|c|c|c|c|}
\hline $\begin{array}{l}\text { Mild } \\
\text { NRS score 1-3 }\end{array}$ & $\begin{array}{l}\text { Moderate } \\
\text { NRS score 4-6 }\end{array}$ & $\begin{array}{l}\text { Severe } \\
\text { NRS score } 7 \text { and above }\end{array}$ & $\begin{array}{l}\text { Intractable pain not amenable to } \\
\text { palliative management }\end{array}$ \\
\hline $\begin{array}{l}\text { - Oral paracetamol } \\
2-4 \mathrm{~g} / 24 \text { hours in four } \\
\text { divided doses } \\
\text { - If patient is not taking } \\
\text { orally, Inj paracetamol } \\
2-4 \mathrm{~g} / 24 \text { hours in four } \\
\text { divided doses } \\
\text { - If neuropathic pain is } \\
\text { present, start gabapentin } \\
100 \text { mg HS and } \\
\text { upward titration by } \\
100-300 \text { mg/24 hours } \\
\text { to a maximum of } \\
2,700-3,600 \text { mg/24 hours } \\
\text { AVOID NSAIDs }\end{array}$ & $\begin{array}{l}\text { - Strategies used for mild + Oral } \\
\text { morphine immediate release } 5 \mathrm{mg} \\
\text { Q4H and breakthrough dose is } 1 / 6 \text { th } \\
\text { the } 24 \text { hour dose. Upward titration by } \\
50 \% \text { of dose everyday } \\
\text { - If patient unable to take orally. Inj } \\
\text { morphine } 1-2 \mathrm{mg} \text { SC or IV every } \\
4 \text { hours } \\
\text { - Consider fentanyl, if patient, has } \\
\text { renal failure. Fentanyl dose is } \\
0.2-0.5 \mu \mathrm{g} / \mathrm{kg} / \text { hour } \\
\text { - Tab/Inj metoclopramide } 10-20 \mathrm{mg} \\
\text { SOS for nausea and vomiting } \\
\text { Tab bisacodyl } 10 \text { mg HS }\end{array}$ & $\begin{array}{l}\text { Strategies used for mild + } \\
\text { Inj morphine } 2-2.5 \mathrm{mg} \\
\text { SC Q4H } \\
\text { - If syringe driver is } \\
\text { available, Inj morphine } \\
10-15 \mathrm{mg} \text { as a } 24 \text { hour } \\
\text { infusion } \\
\text { - Consider fentanyl, if } \\
\text { patient has renal failure. } \\
\text { Fentanyl dose is } \\
0.2-0.5 \mu \mathrm{g} / \mathrm{kg} / \mathrm{hour} \\
\text { Inj metoclopramide } \\
20 \text { mg IV SOS for vomiting } \\
\text { Tab bisacodyl } 10 \text { mg } \\
\text { SOS other strategies for } \\
\text { managing constipation if } \\
\text { patient is unable to take } \\
\text { oral bisacodyl }\end{array}$ & $\begin{array}{l}\text { See Algorithm 5: management } \\
\text { of intractable symptoms }\end{array}$ \\
\hline
\end{tabular}

Algorithm 5: Management of intractable symptoms in patients with serious COVID-19 infections

\begin{tabular}{|c|c|c|}
\hline First line & Second line & Third line \\
\hline $\begin{array}{l}\text { - Midazolam } 2 \text { mg stat } \\
\text { infusion } \\
\text { - Midazolam dose can be incrementally } \\
\text { increased by } 30 \% \text { of the initial dose until } \\
\text { desired sedation is achieved } \\
\text { - If there is no response to incremental } \\
\text { doses or severe distress persists at high } \\
\text { doses of midazolam ( } 75-100 \text { mg/24 hour), } \\
\text { second-line agent should be considered }\end{array}$ & $\begin{array}{l}\text { - Phenobarbitone } 100 \mathrm{mg} \text { stat IV } \\
\text { - Phenobarbitone } 400-800 \mathrm{mg} / 24 \\
\text { hour as continuous IV infusion up } \\
\text { to } 1600 \mathrm{mg} / 24 \text { hour }\end{array}$ & $\begin{array}{l}\text { - On very rare occasions, severe distressing } \\
\text { symptoms not controlled by first and second } \\
\text { line agents, to consider propofol } 0.5 \mathrm{mg} / \mathrm{kg} \text { IV } \\
\text { stat and maintenance of } 1-4 \mathrm{mg} / \mathrm{hour} \text { IV as a } \\
\text { continuous infusion }\end{array}$ \\
\hline
\end{tabular}

